Besides the bulletin, the Review of Applied Entomology continues to be issued by our Imperial Bureau. The summaries of papers from all parts of the world are of great value to workers, who will doubtless be especially grateful to have the essence of much important Russian literature-otherwise unavailablebrought within their reach.

The twenty-first report of the Danish Biological Station to the Board of Agriculture (Copenhagen, I914) consists of an important memoir by Dr. C. J. G. Petersen on the animal communities of the sea-bottom and their importance for marine zoogeography. By means of a new "bottom-sampler" the whole animal population of a square metre of the area under investigation can be brought up in one haul, and the results of numerous "valuations" of the sea-bottom at two hundred stations in the North Sea and the Slkagerrak are set forth in statistical tables and photographs. the latter reduced to scale, giving a vivid impression of the density of the population and the relative abundance of its various members. By this method of research, Dr. Petersen treats the marine fauna as botanists of the ecological school treat the vegetation of an area, and defines an "Echinocardium-Venus" or a "Brissopsis-Turritella" community as characteristic of certain regions. In the use of this method the author believes that "the animals which are not seasonal and which compose an important part of the whole mass of the community owing to number or weight, will presumably be best suited for characteris. ing the community, and must also be considered as giving a good idea of the outer conditions on which the community is dependent."

G. H. C.

\section{FATIGUE STRESSES.}

CINCE Wöhler published in I87 I the results of his tests on the behaviour of steel under repeated stresses a great deal of work has been done in this direction. The experiments of Stanton, Eden, Rose, and Cunningham are well known in this country. The subject is a difficult one, and is complicated by the lack of any satisfactory correlation between the tests. Further, experiments on repeated and alternating stresses take a long time to carry out.

In his memorandum to the Manchester Steam Users' Association, Mr. C. E. Stromeyer gives account of some interesting experiments. Mr. Stromeyer has found that all his tests could be harmonised by arranging for successive fatigue fractures on the same test piece, $I$ in. or $I \frac{1}{2}$ in. apart. From these tests an empirical relationship was derived, and found to be applicable not only to bending fatigue tests, but also to push-and-pull, and to torsion fatigue tests. The empirical formula is $\mathrm{N}=10^{6} \mathrm{C}^{4} \div\left(\mathrm{S}_{n}-\mathrm{Fl}\right)^{4}$, in which $\pm S_{n}$ is the nominal fatigue stresses to which a sample is subjected, $\mathrm{Fl}$ is the fatigue limit of the material, $\mathrm{C}$ is a constant for the given material, and $\mathrm{N}$ is the number of repetitions of the stress $\mathrm{S}_{n}$, which the material will stand before it fractures. The close agreement of this formula with the test results is demonstrated by diagrams given in the memorandum.

An idea for determining the fatigue properties by means of a single test suggested itself, and proved to be so practical that a new machine has now been constructed for the association with which fatigue tests on the improved lines will shortly be undertaken, both as regards push-and-pull stresses, bending stresses, and torsion or shearing stresses. In principle, the new test consists in determining the stress at which the temperature of the test piece begins to rise in consequence of internal friction. There is practically no internal friction in steel up to a certain limit of stress, and hence no heat would be de- veloped in an alternating or repeated stress test within this limit of stress. The test piece was surrounded with a loose sleeve of thick india-rubber, and circulating water passed along the annular space between the test piece and the rubber; delicate thermometers were used to measure the difference in temperature of the inlet and outlet circulating water. At low stresses no difference in temperature was noticed; when a difference of about $0.01^{\circ} \mathrm{C}$. was noticed the fatigue limit was supposed to have been reached, but the fatigue stresses were increased slightly in order to confirm this indication. A considerable difference in temperature was now apparent, but would generally disappear again if the alternating stresses were reduced below the limit. These calorimetrically determined fatigue limits were generally defined very clearly, and may be depended upon as being nearly correct.

Further, the calorimetric fatigue limits agree remarkably well with the fatigue limits $F l$ found by extrapolation of series of tests carried to the point of fracture. Hence it is possible to shorten fatigue testing from several weeks' or months' duration to one or two hours. A single test piece is prepared-duplicates, of course, are desirable-and submitted to gradually increased fatigue stresses until the fatigue limit $\mathrm{Fl}$ is found calorimetrically; then the stresses are increased until a large quantity of heat is evolved, and the alternations of stress are counted up to fracture. These tests fix both $\mathrm{Fl}$ and also the coefficient C.

The method seems very promising, and may lead to a simple workshop fatigue test of considerable practical value being adopted in many works where the time occupied in alternating stress tests has hitherto been a barrier.

\section{THE ROYAL SOCIETY OF NAPLES. ${ }^{1}$}

THE Atti and Rendiconti of the Royal Society of Naples for the past year show what valuable work is being done by this Society. The Atti (corresponding to our Transactions) contain sixteen memoirs, occupying more than five hundred quarto pages. Papers of less importance are inserted in the Rendiconti, which correspond to our Proceedings. Attention should be directed to the very useful and extensive bibliographies which accompany several of the memoirs.

While all the principal sciences are represented, it is to the domain of pure mathematics that the more important work belongs. Mr. G. Gallucci contributes a valuable memoir on configurations (Atti, No. 4); Mr. D. Montesano, others on the Cremonian groups of numbers and the bilinear complexes of conics in space (Nos. 7 and 8); Prof. E. Pascal describes integraphs for differential equations (No. r6), and for the graphical solution of integral equations; Mr. G. Andreoli explains a method of determining superior limits to the moduli of the complex roots of a given algebraic equation. In the Atti (No. Io) Mr. R. Giacomelli. gives a biographical notice of Giuseppe Ballo, a contemporary of Galileo. Among other papers may be mentioned those of $\mathbf{E}$. Guerrieri on the light-curve of Mira Ceti, drawn from numerous observations made during the years $1902-13$, of Dr. M. Fidele on the innervation of the reptilian and batrachian heart (Atti, No. 2), and of F. Zambonini on Vesuvian mineralogy (No. 12).

The condition of Vesuvius since the eruption of Igo6 is the subject of several interesting papers. Prof. G. Mercalli, whose death last March deprived

1 "Atti della Reale Accademia delle Sc enze Fisiche e Matematiche (Società Reale di Napoli)," vol. xv, rq14 ; Rendiconto, vols. xix, xx, June, 1913-June, ז9r4.

NO. 2344, VOL. 94] 
us of an unwearied investigator of Vesuvian phenomena, contributed two notes in July, I913, on recent changes in the crater which, in his opinion, point to an early revival of activity after seven years' rest. Mr. O. De Fiore, in a memoir on the period of repose in Vesuvius which began in I906 (Atti, No. I4), remarks that the great outbursts attract most attention, but urges that the intervening periods of repose are also deserving of study, for it is through their investigation that we may be led to foresee a coming revival of activity. He distinguishes three principal, though overlapping, phases in the Vesuvian period of repose, to the first of which-the degradation of recent forms-the present memoir is devoted. Lastly Dr. A. Malladra, of the Vesuvian observatory, describes the solfatara of the Atrio del Cavallo, which separates the modern cone of the volcano from the cliffs of Monte Somma.

\section{THE AUSTRALIAN MEETING OF THE BRITISH ASSOCIATION.}

\section{SECTION L.}

EDUCATIONAL SCIENCE.

Opening Address by Prof. John Perry, D.Sc., LL.D., F.R.S., President of the Section.

I WISH to make some general remarks upon the science of education. As in the chapter which was entitled "The Snakes of Iceland," and which merely consisted of the sentence, "There are no snakes in Iceland," I might finish this Address at once by saying "There is no science of education." There is the art or practice of teaching or pedagogy, just as there used to be the art of engineering. It was only slowly that the subject of Section G, the Science of Engineering, was created; but the subject of Section $\mathrm{L}$, this section, has still to be created. In the creation of a science we first and for long periods have the observation of detached phenomena and disputes about them, because the phenomena seem complex, having no obvious connection with one another; then experiments simplify things, and gradually the science is created by inductive reasoning and research. In education, observation and disputes have occupied much time, and we cannot say that the phenomena have become much simplified by such experiments as have been made. Every man in the street considers that his opinions on education are as good as those of anybody else. I suppose that almost nobody would refuse to make an after-dinner speech on any kind of education, whereas he would not dream of speaking about geometry, or chemistry, or physics, or physiology unless he had studied these subjects. Any ordinary citizen thinks himself fit to be a member of the governing body of a school or college, and the disasters due to this belief are worse than what would occur if we gave to such men the command of ships. The ordinary man, especially the Parliamentary man, who thinks that the members of a committee on some scientific business ought all to be non-scientific men, will jeer at this statement, but it is, nevertheless, fatally true.

It is possible that, even if we had the science, the pedagogues would pay no attention to its principles, just as there are industrial chemists in London whose businesses are dwindling because they pay no attention to the science of chemistry. Pedagogy is in a worse condition than industrial chemistry, because chemical products can be easily tested as good or bad, whereas the pedagogic product is exceedingly difficult to test. The customer is the worst of judges. Those soul-destroying cheap schools described by NO. 2344 , VOL. 94]
Mr. Wells used to be very numerous; they are still, many of them, in existence. Every observant person knows of these places, to which small shopkeepers still send their sons, because they are genteel and cheap, and because Latin is taught, and perhaps French. Did any such parent ever object to the result of the schooling? Even when a boy has become a man, neither he nor his father knows whether his defects or merits are due to bad or good schooling. Please read Mr. Wells's book about Mr. Polly. Again, the reforms in pedagogy which, with Dr. Armstrong, I have been clamouring for during the last thirty years, would cause the best-known pedagogues to scrap all their machinery, and so to lose nearly the whole of their invested capital. Even when they are not influenced by the idea of losing money, these men cannot be made to believe in the necessity for reform any more than the Central African worshippers of hideous idols can be converted, for with just as much intensity do they worship the product of our present schools and colleges. The pedagogue is not alone in his false worship; this is the day of small men, common-place men, men manufactured like so many buttons, so that it is almost impossible for a great man to appear; everybody is compelled by custom or by law to go to school, and the school ideal is just as false and mean and material as any false religion ever was. Every clever man who has gone to a public school and to Oxford or Cambridge worships the system which has taken from him his spiritual birthright, his individuality, his initiative, his originality, his common-sense, his power to think for himself--yes, and I may say his belief in himself. He has become too much like a sheep, ready to follow the bell-wether; he is a man who has greatly lost his soul. Average boys leaving a public school all speak in the same way, in the same words, about anything. They are nearly as much alike as things manufactured by the same machine. An expert easily tells from what school a boy has come, because there is nothing left in his mind which is not common to the whole school.

The education given in England to boys until they leave school at twenty, and until they graduate at a university, is almost altogether classical: that is, founded on the language and literature of Greece and Rome. On the day on which I wrote this there was a report of an address in the Times which said that this study was the cause "of all imaginative aspirations, of all intellectual interests"; "it enabled men to appreciate not only Homer and 'Virgil, but equally Dante and Milton, Goethe, and Wordsworth, all the great thoughts of all ages and all lands, and to be awake to the movements of their own day." It said that this study made a man "a better man of business, a better lawyer, a better merchant, a better stockbroker, a less hidebound politician." "Those who would banish Greek or would make it the peculiar property of a select few, did a grave disservice to the whole cause of intellectual and spiritual life." The writer then described his own diligent reading in the train every morning; in the course of a few months he had read the "Iliad," the "Odyssey," the "Aeneid," five books of Livy, and the whole of "Catullus" and "Martial." It seems almost as if he must have all extant classical literature off by heart. He must have enormous satisfaction as he sits in the train looking at the quite common travellers who are reading about the affairs of the nation in English newspapers. I quote the above statements because they are typical. All our classical friends say that sort of thing. But I do not pay much attention to them, because I know that the greatest classical scholars only devote themselves to editing 